\title{
Micro Preemie with the Earliest Gestational Age and the Lowest Birth Weight that Survived in ICU, Dhaka Shishu (Children) Hospital, Bangladesh
}

\author{
MS HOQUE ${ }^{\mathrm{a}}$, M RAHMAN ${ }^{\mathrm{b}}$, M HUSSAIN $^{\mathrm{c}}$, ASMNU AHMED $^{\mathrm{d}}$
}

\begin{abstract}
Summary:
Prematurity is a common neonatal problem in developing countries and is associated with high mortality and both immediate and long-term morbidities. More a baby is premature more is the chance of mortality. With the advent of modern supportive care favorable outcome has been observed in extremely premature babies in developed countries, but the outcome is not satisfactory in developing countries. Recently, an incredibly low birth weight (456 grams) micro preemie was successfully managed in Dhaka
\end{abstract}

\section{Introduction:}

Prematurity and low birth weight (LBW) are significant risk factors for survival of the neonate and are associated with high perinatal mortality. The latest regional estimates of LBW range from $25 \%$ in South Asia, where more than half of the world's LBW infants are born, to $10 \%$ and $12 \%$ in Sub-Saharan Africa and Latin America, respectively. ${ }^{1}$ Low birth weight (LBW) is one of the major health issues of children in developing countries, and also one of the most important challenges in maternal and child health. Its significance may be ascribed to numerous factors - high incidence, association with physical and mental retardation, high risk of perinatal and infant mortality and morbidity, the

a. Dr. Md. Shafiul Hoque, Associate Professor of Paediatrics, Bangladesh Institute of Child Health, Dhaka Shishu Hospital

b. Dr. Mobashshera Rahman, Medical Officer, Dhaka Shishu Hospital

c. Prof. Manzoor Hussain, Professor of Paediatrics, Bangladesh Institute of Child Health, Dhaka Shishu Hospital

d. Prof. S.M. Nawshad Uddin Ahmed, Professor of Paediatrics, Bangladesh Institute of Child Health, Dhaka Shishu Hospital

Address of Correspondence: Prof. A.S.M. Nawshad Uddin Ahmed, Professor of Paediatrics, Bangladesh Institute of Child Health, Dhaka Shishu Hospital, Sher-e-Bangla Nagar, Dhaka-1207, Cell: 01552372200, E-mail: dr_nawshad@yahoo.com

Received: 25 August 2015

Accepted: 23 July 2017
Shishu Hospital. With round the clock care at the hospital's Neonatal Intensive Care Unit she was tipping the scales and discharged at the age of three months, weighing 1128 grams. To the best of our knowledge, this is the lowest birth weight baby survived in our country, an exceptional achievement and a milestone in newborn care in Bangladesh.

Key words: Prematurity, Incredibly Low Birth Weight, Neonatal Intensive Care Unit, Outcome.

(J Bangladesh Coll Phys Surg 2017; 35: 142-146)

excessive cost of intensive care units and its association with socio economic impact and under development. ${ }^{2}$

Low birth weight infants are those born weighing less than $2500 \mathrm{gm}$. These are further subdivided into Very Low Birth Weight (VLBW): birth weight $<1,500$ gm; Extremely Low Birth Weight (ELBW): birth weight $<1,000$ gm, Incredibly Low Birth Weight (ILBW): birth weight $<750$ gm. 3,4

Obstetrical history (LMP, sonographic dating) and newborn physical examination for maturational age by Ballard or Dubowitz score are critical data to differentiate premature LBW from more mature intrauterine growth-restricted LBW infants (IUGR). This may be crucial as infants who are IUGR, seem to have a survival advantage. ${ }^{5}$

The prognosis of low birth weight (LBW) infants in developing countries has improved dramatically over the last decades with advances in perinatal medicine, albeit the outcomes of ELBW and ILBW still remain disappointing. There have been reports of up to $80 \%$ survival rate of babies born at 24 weeks in developed countries (e.g., Japan), ${ }^{6}$ the rate is much lower in Southeast Asia. There is, in fact no reports of survival of any infant born at 24 weeks or earlier, weighing 500 grams or less in Bangladesh. 
Here we report a case of preterm ILBW baby who was successfully managed in the NICU of Dhaka Shishu (children) Hospital (DSH), Bangladesh. This outstanding achievement is a milestone in newborn care in our country.

\section{Case summary:}

A female baby was delivered in a clinic by normal vaginal delivery on 24-02-2013 at 11:00 AM at 24 weeks of gestational age (by date) due to premature rupture of membrane followed by premature labor. Birth weight of the baby was 480 grams. Mother was 24 years old and this was her first pregnancy. She was not known to have hypertension, diabetes mellitus or any other illness.

The baby received routine delivery room care including initial resuscitation by oropharyngeal suction and oxygen inhalation. Then she was shifted to NICU of that clinic. During the 6-daystay at that clinic, she did not receive surfactant, mechanical ventilator care or CPAP. Parents transferred the baby to DSH ICU on $6^{\text {th }}$ day of her life, hoping for better care at a much substantiated cost.

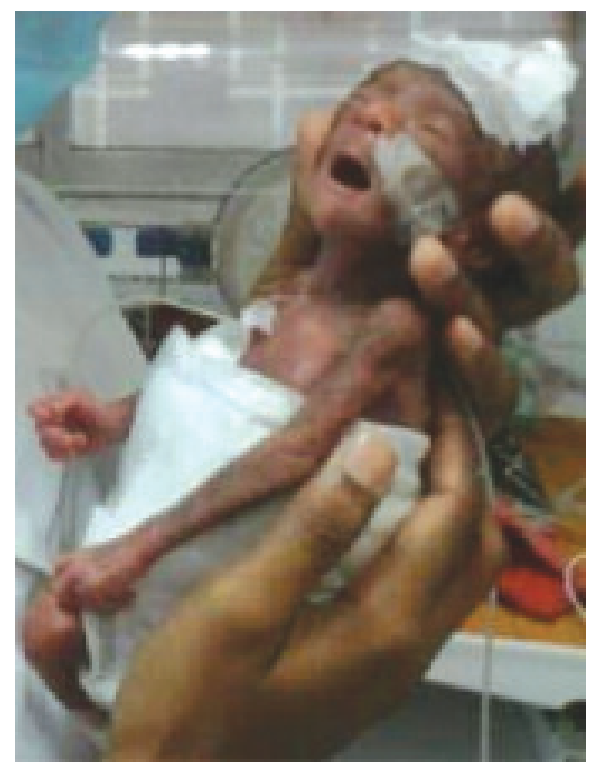

Fig.-1: At the age of day-6 (weight $456 \mathrm{gm}$ )

On admission in DSH NICU, the baby was conscious, mildly dyspnoeic with respiratory rate of 64 breaths/ min, moderate air entry in both lung fields and heart rate of 160 beats $/ \mathrm{min}$. She maintained a SPO, of $96 \%$ with $4 \mathrm{~L} / \mathrm{min}$ supplemental $\mathrm{O}_{2}$ delivered by face mask.
Her weight was 456 gm, occipito-frontal circumference $21.8 \mathrm{~cm}$ and length $30 \mathrm{~cm}$. She was icteric (serum bilirubin $8.33 \mathrm{mg} / \mathrm{dL}$ ) and received phototherapy while being cared for in a closed incubator. Baby's parents were appropriately counseled regarding the poor outcome of a 24-weeker baby weighing less than 500 grams and they opted for not ventilating the baby mechanically if her condition ever worsened to the point of requiring it.

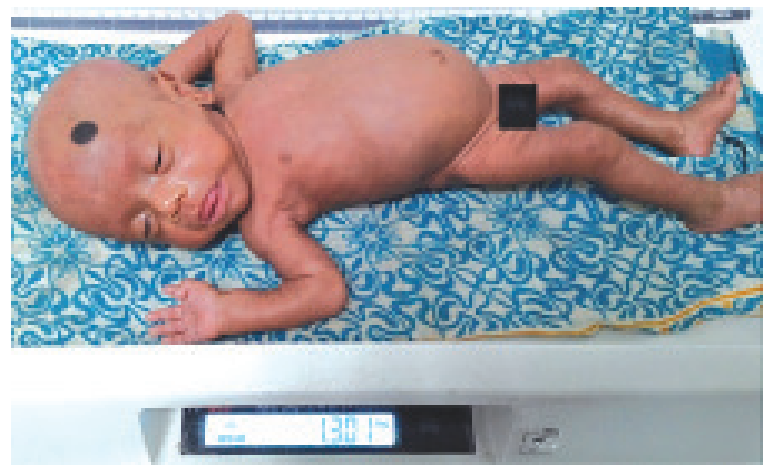

Fig.-2: At the age of 104 days (weight $1301 \mathrm{gm}$ )

She was on parenteral nutrition with glucose and amino acids since admission, small volume enteral feeding was started with expressed breast milk by NG tube on D13 (weight 449 gm)of her age. The amount was gradually increased and full enteral feeding was achieved on D 59 (weight $684 \mathrm{gm}$ ) as there had been interruptions on 5 occasions due to regurgitation, aspiration, vomiting and feed intolerance. On many occasions she had regurgitated the milk and aspirated. On one of these episodes she was intubated and trachea was suctioned, but was extubated soon after the procedure. Vitamins (including vit. D), Folic acid, and calcium supplementation was started on D21 and continued till one month after discharge.

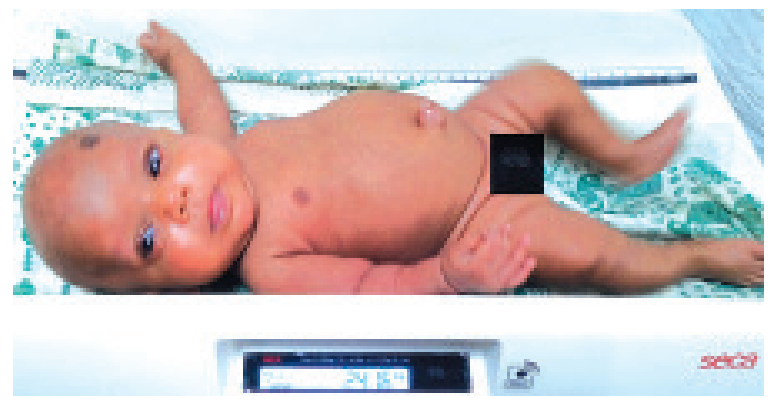

Fig.-3: At the age of 139 days (weight $2416 \mathrm{gm}$ ) 
She received injections ceftazidime and Amikacin since Day1 and was replaced with Meropenemon Day 8 and continued for 21 days till D 27 (weight $508 \mathrm{gm}$ ) of her age, when it was changed to Tazobactum and Piperacillin as her condition worsened with an episode of prolonged apnea requiring resuscitation with bag and mask ventilation. Her condition further deteriorated on Day 40 (weight 622gm) and she had an episode of apnea followed by hypoxemia $\left(\mathrm{SPO}_{2} 40 \%\right)$. This episode also required CPR using Ambu bag. Her antibiotic was then changed to Cefepime and Netromycin. Nasogastric feeding was stopped on Day 41 as she had frequent apneas. She was not mechanically ventilated according to her parents' will. She was gasping and we did not quite expect her to survive. Her condition however, improved the next day and NG feeding was restarted. Netromycin was omitted after 14 days and Cefepime was continued for 21 days till Day 62 (weight $710 \mathrm{gm}$ ) of her age, then it was changed to Cefotaxime which was continued for another 21 days.

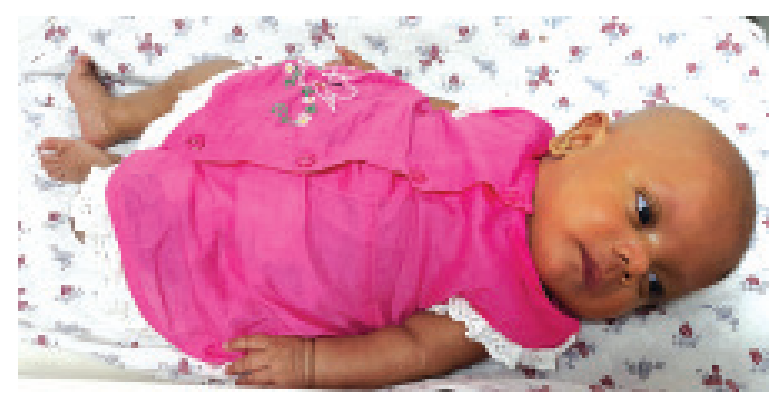

Fig.-4: At the age of 153 days (weight $2811 \mathrm{gm}$ )

The infant was handled very minimally and blood tests were done only on several very urgent occasions. She initially had altered renal function (blood urea $22.5 \mathrm{mmol} / \mathrm{L}$ and $\mathrm{S}$. creatinine $157.3 \mu \mathrm{mol} / \mathrm{L}$ on day 6 ) which improved with conservative management (blood urea and S. creatinine level was $16.1 \mathrm{mmol} / \mathrm{L}$ and $97.0 \mu \mathrm{mol} / \mathrm{L}$ respectively on day $9,1.4 \mathrm{mmol} / \mathrm{L}$, $36.5 \mu \mathrm{mol} / \mathrm{L}$ on day 9$)$.

She received pentaglobulin, fresh frozen plasma (FFP) and small volume blood transfusions in several times. She was oxygen dependent till D 77 (weight 914gm) of her age. Although there had been suspicions of bronchopulmonary dysplasia, no medical treatment was instituted. Supplemental oxygen could finally be stopped on $78^{\text {th }}$ day of age. The damage however was done already. She had stage III retinopathy of prematurity (ROP) detected on screening and immediate treatment with laser augmentation was initiated while still in ICU. A cranial ultrasound was done on D79 that revealed mild cerebral edema, but no evidence of intraventricular hemorrhage.

The baby was transferred at the age of 97 days from NICU to cabin when her weight was $1128 \mathrm{gm}$, length $34 \mathrm{~cm}$ and head circumference $27.8 \mathrm{~cm}$. Finally she was discharged after three days. At the time of discharge, her echocardiography revealed a patent foramen ovale (PFO) and good biventricular function, her cranial ultrasound revealed normal findings (previous cerebral edema had resolved). Her thyroid function tests were normal. However, she still had ROP stage III (under treatment).

She was being followed up weekly after discharge and was found to have gaining appropriate growth and development. On last follow-up visit at the age of 153 days, her weight, length and OFC was $2811 \mathrm{gm}, 42 \mathrm{~cm}$ and $32.7 \mathrm{~cm}$ respectively and was on exclusive breastfeeding. Ophthalmological evaluation revealed no signs of ROP.
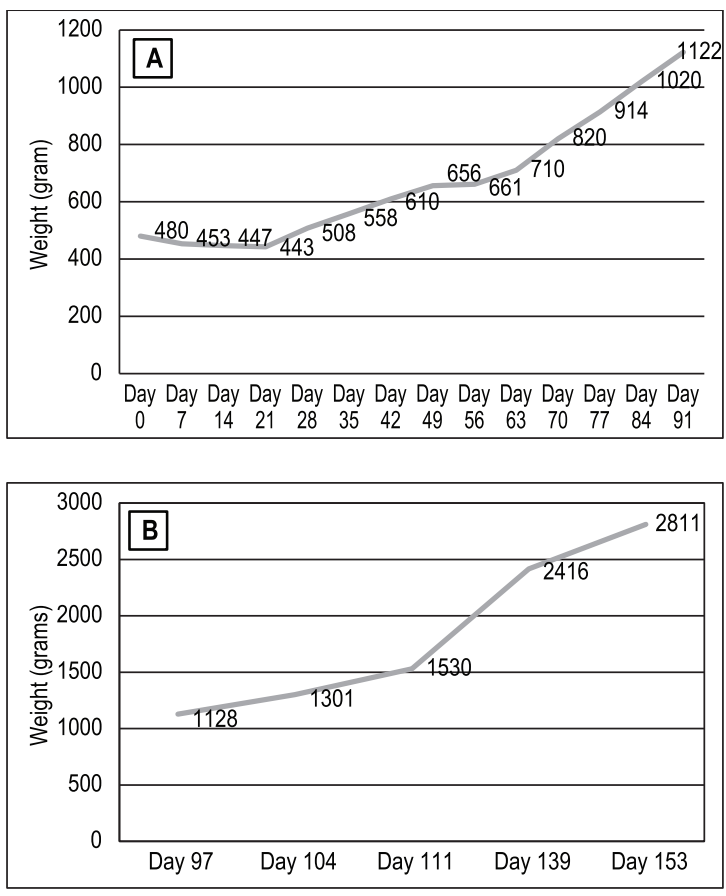

Fig.-5: Weight chart of the baby (gm) during hospital stay (A) and after discharge (B) 


\section{Discussion:}

The likelihood of survival of premature infants often depends on gestational age and birth weight. ${ }^{7}$ For any given duration of gestation, the birth weight is inversely related to the neonatal mortality; for any given weight the shorter the gestational age the higher the neonatal mortality. ${ }^{6}$ However, many other perinatal factors also play vital roles in influencing the outcome of ELBW infants such as race, ${ }^{8}$ level of neonatal care, ${ }^{9}$ antenatal steroid injections, ${ }^{5,10}$ and mode of delivery. ${ }^{11}$ It has been well known that antenatal steroid administration improves the prognosis as well as survival, ${ }^{10}$ whereas vaginal delivery in nonvertex presentation is an adverse factor. ${ }^{11,12}$

According to the National Institute of Child Health and Human Development(NICHD) National Research Network (NRN): Extremely Low Birth Weight outcome data, the probability of survival of a baby in NICU may be positively influenced by genetic sex of the baby (females have a better outcome), exposure to antenatal corticosteroids, singleton pregnancy, intensive care and higher birth weight (per each $100 \mathrm{~g}$ increment). These factors are also associated with reductions in the risk of profound or any neurodevelopmental impairment. ${ }^{13}$ Another important observation was that majority of the delivery room and NICU survivors at birth weights less than 500 grams were SGA/IUGR females. ${ }^{5}$ This infant had some of the good prognostic factors like being a female, born as singleton and being SGA. She had some adverse prognostic factors as well e.g., she was not exposed to antenatal steroids and was delivered vaginally. ${ }^{12}$

Complications of ELBW infants are numerous. Important short term problems are respiratory distress syndrome, necrotizing enterocolitis, nosocomial infection, intraventicular hemorrhage, ROP, patent ductus arteriosus etc. Long term effects include chronic lung disease, failure to thrive, cerebral palsy, visual and hearing impairment etc. ${ }^{14}$

Minimal handling and intervention done in this remarkable female infant probably made a huge difference. The intensive medical care, including excellent nursing care available in NICU, contributed to minimal complications experienced in this infant. It was in fact a miracle that this 24 week old infant, in spite of not being exposed to antenatal corticosteroids and postnatal surfactant, did not show signs of severe RDS (clinically and radiologically). Ventilator care was withheld, although it would normally have been given to other neonates in similar respiratory condition.

The question of providing life support or not for premature infants at the threshold of viability is still a matter of controversy. During the past two decades, survival rates have increased substantially because of advances in knowledge, medical technology and therapeutic option but long-term morbidity rates continue to be high. ${ }^{15,16}$ Indeed, several studies have suggested that the incidences of long-term sequelae including neurodevelopmental disabilities may not have decreased among survivors. ${ }^{15,16}$ With respect to offering life support, various authors and societies conclude differently, on the basis of their interpretations of available data concerning cost of care, burdens to the patient, family and society, and long-term outcomes. The American Academy of Pediatrics suggests that parental choice based on thorough information should be respected within the limits of what is medically feasible and appropriate, but definitions of those limits are vague, except that non-initiation of resuscitation is considered appropriate for newborns of $<23$ weeks of gestation and/ or birth weight (BW) of $<400$ g. ${ }^{17}$

Until now, there is no report on the lowest birth weight baby survived in Bangladesh. The lowest birth weight baby survived in KSA was a 26 weeker weighing 520 grams. ${ }^{18}$ The scenario in the developed countries is different where lowest birth weight babies that survived weighing less than 300 grams. ${ }^{19}$

This infant will need to be followed up over years to see whether or not she develops severe long term consequences and becomes neurodevelopmentally handicapped. Only then can the efforts of trying and saving a 24-week-old infant weighing 456 grams can be justified.

\section{Acknowledgements:}

We thank the NICU physicians and nurses for their constant supervision and relentless endeavor in caring the baby. We would also like to express our gratitude to the parents of the child for their patience and wholehearted cooperation over a long period, and allowing us to publish the case report.

\section{Reference:}

1. UNICEF. The State of the World's Children 1998: a UNICEF report. Malnutrition: causes, consequences and solutions. Nutr Rev 1998; 56: 115-23. 
2. Yasmeen S, Azim E. Status of low birth weight at a tertiary level hospital in Bangladesh for a selected period of time. South East Asia Journal of Public Health 2011: 1: 24-27.

3. Stoll BJ, Chapman IA. The High-Risk Infant. In: Klieg man, Behrman, Jenson, Stanton editors. Nelson Text book of Pediatrics. 19th ed. Philadelphia USA: Saunders Elsevier; 2011: pp 552-64.

4. $\quad$ Nagger ME. Pediatric Clinical diagnosis. $6^{\text {th }}$ ed. New Delhi: Jayvee Brothers Medical Publishers (P) Ltd; 2008.

5. Lucy JF, Rowan CA, Shino P, Wilkinson AR, Kilpatrick S, Payne NR et al. Fetal Infants: The Fate of 4172 Infants With Birth Weights of 401 to 500 Grams - The Vermont Oxford Network Experience (1996-2000).Pediatrics 2004;113: 1559.

6. Ogawa M, Matsuda Y, Canada E, Konno J, Minoru M, Makino $\mathrm{Y}$ et al. Survival Rate of Extremely Low Birth Weight Infants and Its Risk Factors: Case-Control Study in Japan. Obstetrics and Gynecology 2013, 2013: 873563.

7. Marketed T, Karees PI, Rønnestad A, Reigstad H, Lossius K, Medbø S, et al. Early death, morbidity, and need of treatment among extremely premature infants. Pediatrics 2005; 115 : 1289-98.

8. Mathews TJ, Miniño AM, Osterman MJK, Strobino DM, Guyer B. Annual summary of vital statistics: 2008. Pediatrics 2011; 127: 146-57.

9. Lasswell SM, Barfield WD, Rochat RW, Blackmon L. Perinatal regionalization for very low-birth-weight and very preterm infants a meta-analysis. JAMA 2010; 304: 992-1000.

10. The effect of antenatal steroids for fetal maturation on perinatal outcomes-interim draft statement. NIH Consens Statement Online 1994 Feb 28-Mar 2; 12:1-24. Available from: http:// consensus.nih.gov/1994/1994 Antenatal Steroid Perinatal 095html.htm. Accessed on: 07 July 2015.

11. Carlo WA, McDonald SA, Fanaroff AA, Vohr BR, Stoll BJ, Ehrenkranz RA, et al. Association of antenatal corticosteroids with mortality and neurodevelopmental outcomes among infants born at 22 to 25 weeks' gestation. JAMA 2011; 306: 2348-58

12. Lee HC, Gould JB. Survival advantage associated with cesarean delivery in very low birth weight vertex neonates. Obstetrics and Gynecology 2006; 107: 97-105.

13. Deulofeut R, Sola A, Lee B, Buchter S, Rahman M, Rogido M. The impact of vaginal delivery in premature infants weighing less than 1,251 grams. Obstetrics and Gynecology $2005 ; 105 ; 525-31$.

14. Tyson JE, Parikh NA, Langer J, Green C, Higgins RD. Intensive care for extreme prematurity-moving beyond gestational age. $N$ Engl J Med 2008; 358: 1672-81

15. Eichenwald Eric C. Care of the extremely low birth weight Infant. In: Taeusch, Ballard, Gleason, editors. Avery's Disease of the Newborn. 9th ed. Philadelphia. Elsevier; 2012: pp 41026.

16. Vohr BR, Wright LL, Dusick AM, Mele L, Verter J, Steichen JJ, et al. Neurodevelopmental and functional outcomes of extremely low birth weight infants in the National Institute of Child Health and Human Development Neonatal Research Network, 1993-1994. Pediatrics 2000; 105: 1216-26

17. Wood NS, Costeloe K, Gibson AT, Hennessy E, Marlow N, Wilkinson A. The EPICure study: growth and associated problems in children born at 25 weeks of gestational age or less. Arch Dis Child Fetal Neonatal Ed 2003; 88: F492-F500.

18. MacDonald H, American Academy of Pediatrics, Committee on Fetus and Newborn. Perinatal care at the threshold of viability. Pediatrics 2002; 110: 1024-27.

19. Rahman AFMM, Solanky J, Mridha MA, Amrei AA. Lowest Birth Weight Baby Survived in Abha General Hospital, Abha, K S A. Bangladesh J Child Health 2011; 35: 71-74. 